\title{
International Journal of Emerging Trends in Science and Technology
}

DOI: https://dx.doi.org/10.18535/ijetst/v6i12.01

\section{Original Research Article}

\section{Dental Malpractice in Implant Dentistry in Saudi Arabia}

\author{
Authors
}
Rahaf Al-Safadi, ${ }^{1,2 *}$ Riham Al-Safadi, Reef Al-Safadi, Sultan Al-Jahdali, ${ }^{2}$ Abdulrahman Al-Hamidi, ${ }^{2}$ Bandar Al-Khuraisi, ${ }^{2}$ Talal Al-Malki, ${ }^{2}$ Thamer Al-Gannass, ${ }^{2}$ Mutaz Al-Arjani, ${ }^{2}$ Hasan Al-Alawi ${ }^{2}$
${ }^{1}$ Department of Preventive Dentistry, College of Dentistry, Riyadh Elm University, Riyadh, Kingdom of Saudi Arabia
${ }^{2}$ University Dental Hospital, College of Dentistry, Riyadh Elm University, Riyadh, Kingdom of Saudi Arabia
*Corresponding Author

\section{Rahaf Al-Safadi}

Department of Preventive Dentistry, University Dental Hospital, College of Dentistry, Riyadh Elm University, Riyadh, Kingdom of Saudi Arabia

Email: dent.sci.research@gmail.com

\begin{abstract}
Aim: The aim of this study was to detect and analyze dental malpractice in the field of implant dentistry in the Kingdom of Saudi Arabia.

Materials and Methods: 106 patients aged $\geq 18$ years with at least one professional malpractice in implant dentistry done in dental health premises in Saudi Arabia were included in the study. Clinical and radiographic examinations were used to detect preoperative (diagnosis and treatment planning), intraoperative (implant insertion), and postoperative (postsurgery and prosthesis) complications. The data obtained including age and gender were documented in a patient examination form then statistically analyzed using Chi-Square Test and Spearman's Correlation Coefficient.

Results: The percentages of patients were equally divided among the preoperative, intraoperative, and postoperative phases $p>0.05$. More than half of the patients were females (61.3\%). The majority of the patients were in the age group 50-60 years. Also, the majority of the patients had implants with malpractice placed in the posterior region. Exactly half of the patients had implants with malpractice placed in the maxilla. In addition, exactly half of the patients had technical errors violating the surrounding structures; $(37.7 \%)$ of the patients had damage to adjacent tooth and (11.3\%) had inferior alveolar nerve damage; also, (4.7\%) of them had sinus penetration. Furthermore, at the patient level, age and gender were not related to implant failure, and (75.5\%) of the patients had implant failure. With respect to peri-implantitis, patients $\geq 50$ years of age were more than patients $<50$ years of age. However, gender and maxilla were not related to peri-implantitis. The prevalence of peri-implantitis was $20.8 \%$ at the patient level. In partially edentulous patients, implant fracture was $(1.17 \%)$ at the implant level.

Conclusion: Implant malpractice equally occurred among the preoperative, intraoperative, and postoperative phases.

Keywords: Failure, Implant, Intraoperative, Malpractice, Peri-implantitis, Postoperative, Preoperative
\end{abstract}

\section{Introduction}

"Dental malpractice is the failure of a dental professional to follow the accepted standards of practice of his or her profession, resulting in harm to the patient. Usually, proof of failure to comply with accepted standards of dental practice requires the testimony of someone with expertise in dentistry." The National Institutes of Health, Consensus 
Development Conference Statement in 1978 on Dental Implant: Benefits and Risk concluded that "clinically, thousands of patients have been treated with dental implants for years and there is no question that many received long-term benefits." The report further clarified that "some implants, on the other hand, fail in patients within six months; some have resulted in extensive bone loss and produced irreversible defects and complications." 2

The report released the guidelines and restrictions for the use of different types of implants, encouraged clinical trials on various types of implants, defined the criteria for success considering a successful implant should provide functional services for five years in $75 \%$ of the cases, recommended eleven criteria for removing an implant such as persistent pain, mobility, progressive bone loss, infection, intolerable dysthesia, oro-antral or oro-nasal fistulae, possible irreversible damage to adjacent tooth, implant fracture, aesthetics. ${ }^{2,3}$ It also pointed out to the unrestricted use of implants inadequately tested in addition to poor patient selection as predictors to implant failure. ${ }^{2}$ Afterwards, in 1986, Albrektsson et $\mathrm{al}^{4}$ defined the criteria for implant success, which was modified later by Roos et $\mathrm{al}^{5}$ in 1997 . This criteria serve as a substantial standard for inspecting new types of implants in both clinical and research aspects.

The updated criteria for implant success include ${ }^{6,7}$ :

- No mobility of the implant

- No radiographic peri-implant radiolucency

$-\leq 1.0 \mathrm{~mm}$ bone loss during the first year of loading

$\bullet \leq 0.2 \mathrm{~mm}$ annual bone loss following the implant's first year of function

- Absence of pain and pathology around the implant

- Functional survival of the implant for 5 years in $90 \%$ of cases and for 10 years in $85 \%$ of cases.

Nowadays, esthetically acceptable implant has been added as a parameter to the definition of implant success and contrarily implant failure. ${ }^{6,7}$

In 2004, the report of the American Dental Association Council on Scientific Affairs addressed the high success rates of different implant designs in several clinical settings, the factors contributing to increased risk of implant failure, and dental implantology as a comprehensive process of patient care. Also, the council indicated to a list of products available in market that had received the ADA seal of acceptance. The council recommended clinicians to adhere to the current best evidence when using implantation therapies and systems. It also recommended evaluators to employ common and consistent criteria when assessing the outcomes of dental implant treatments. ${ }^{8}$ The aim of this study was to detect and analyze dental malpractice in implant dentistry in Saudi Arabia.

\section{Materials and Methods}

\section{Ethical approval}

The study was registered with the research center of Riyadh Elm University (FRP/2019/107) and received ethical approval from the institutional review board of the same institution (RC/IRB/2019/189).

Selection of the content for analysis and statistical analysis

The classification of complications in implant dentistry was adapted based on Chee and Jivraj, ${ }^{9}$ Chen and Buser, ${ }^{10}$ Pi-Anfruns, ${ }^{11}$ Pinchi et al, ${ }^{12}$ and Palmer et $\mathrm{l}^{13}$ (Table 1).

Also, based on Byrne, ${ }^{7}$ the following spatial considerations, safety guidelines, and implant failure criteria were followed for the detection of implant malpractice cases:

Mesio-distal space between implants and adjacent crowns and roots / between adjacent implants

A mesio-distal space of 1.5-2.0 mm of bone should remain between the greatest diameter of the implant and the crowns and roots of adjacent teeth with a minimum of 1.0 to $1.5 \mathrm{~mm}$ of distance mesially and distally. ${ }^{7}$ In the present study, insufficient space from the tooth to the implant less than $1.0 \mathrm{~mm}$ was considered for the detection of errors. "2.0-3.0 mm bone should remain between adjacent implant platforms."7 
Table 1: Classification of complications in implant dentistry*

\begin{tabular}{|c|c|}
\hline Category & Item \\
\hline $\begin{array}{l}\text { Preoperative technical errors (errors during } \\
\text { diagnosis and treatment planning) }\end{array}$ & $\begin{array}{l}\square \text { Poor patient selection (eg, periodontitis, } \\
\text { smoking, diabetes, poor oral hygiene) } \\
\square \text { Diagnostic errors (eg, poor anatomical analysis } \\
\text { of implant site, poor occlusal analysis, such as } \\
\text { interocclusal space, opposing dentition, type of } \\
\text { occlusion) } \\
\square \text { Inappropriate treatment planning (eg, incorrect } \\
\text { number of implants, incorrect dimension of } \\
\text { implants, incorrect spacing of implants, incorrect } \\
\text { length of implants) }\end{array}$ \\
\hline $\begin{array}{l}\text { Intraoperative technical errors (technical } \\
\text { operative errors during implant placement) }\end{array}$ & $\begin{array}{l}\square \text { Adjacent soft tissue damage } \\
\square \text { Bleeding } \\
\square \text { Broken instruments } \\
\square \text { Damage to adjacent tooth } \\
\square \text { Inferior alveolar nerve damage } \\
\square \text { Sinus penetration } \\
\square \text { Implant positional failure** }\end{array}$ \\
\hline $\begin{array}{l}\text { Postoperative technical errors (postsurgical and } \\
\text { prosthetic errors) }\end{array}$ & $\begin{array}{l}\square \text { Infection } \\
\square \text { Wound dehiscence } \\
\square \text { Peri-implantitis } \\
\square \text { Implant failure } \\
\square \text { Prosthetic complications (eg, veneer fracture, } \\
\text { framework or denture fracture, implant fracture, } \\
\text { implant failure forcing change in bridgework or } \\
\text { denture) }\end{array}$ \\
\hline
\end{tabular}

* Some cases had more than one detection of claimed error.

** Implant positional failure due to poor surgical execution

Vertical space for implant prosthesis (crown / denture) from occlusal plane to implant platform A height of $5.0-7.0 \mathrm{~mm}$ or $5.0-8.0 \mathrm{~mm}$ with a minimum of $5.0 \mathrm{~mm}$ between the implant platform and the opposing teeth is preferable for crowns and bridges. Also, a vertical distance of $10.0-12.0 \mathrm{~mm}$ with a minimum of $10.0 \mathrm{~mm}$ from the implant platform or the bony ridge crest to the occlusal plane is required for implant overdentures. ${ }^{7}$

\section{Bucco-lingual bone volume}

At least $1.0 \mathrm{~mm}$ of bone should remain buccally and lingually after implant placement to avoid the risk of bone dehiscence or fenestration during surgery. Ridge grafting is recommended for narrow ridges. ${ }^{7}$
Implant position: Aesthetic and safety guidelines:

- Ensure that the implant platform is flush with the alveolar bone crest (which may need flattening). Polished necks are designed to extend above the crest.

- Between 1.0 and $2.0 \mathrm{~mm}$ of bone should surround the implant bucco-lingually and mesio-distally.

- Between 2.0 and $3.0 \mathrm{~mm}$ of bone should remain between adjacent implant platforms.

- The implant must be positioned at least $2.0 \mathrm{~mm}$ away from nerve canals.

- Between 1.0 and $2.0 \mathrm{~mm}$ bone should remain between the implant and the maxillary antrum, the floor of the nose, and the mandiblular inferior border or cortical plates.

- Allow $5.0 \mathrm{~mm}$ between an anterior implant and the mental foramen to allow for the posterior loop of the mental nerve. ${ }^{7}$ 


\section{Implant failure:}

An implant may be considered a failure

if it is unusable for its intended purpose for the following reasons:

- It has lost, or is losing, its osseointegration.

- It is malpositioned, making it unusable.

- It is impinging on vital anatomic structures (requiring removal).

- It has fractured. ${ }^{7}$

In addition, esthetically acceptable implant was added as a parameter to the definition of implant success and contrarily implant failure. ${ }^{7}$

The inclusion criteria applied for case selection were: (1) patients aged $\geq 18$ years (2) patients with at least one professional malpractice in implant dentistry (3) professional malpractice in implant dentistry of the substandard dental implant treatments done in dental health premises (hospitals, polyclinics, private clinics) in the Kingdom of Saudi Arabia. The exclusion criterion was: cases with unacceptable diagnostic quality of radiographs. The sample of the study was randomly selected. The term case was used in this study to indicate to one patient with at least one implant malpractice, and some cases had more than one detection of claimed error. The study was carried out from September 2019 to December 2019. The patient consent was taken on an informed consent statement form for clinical studies. Clinical and radiographic examinations were applied including panoramic and periapical radiographs in addition to threedimensional imaging CBCT. All cases were subjected to consultations of experienced implantologists. The data obtained including age and gender were documented in a patient examination form then statistically analyzed using Chi-Square Test to test the contingency of the variables and Spearman's Correlation Coefficient to test the association between categorical variables; the statistical parameter was estimated (confidence intervals for proportions at confidence level 95\%). All statistical analyses were performed using the IBM SPSS Statistics version 20 data processing software. The significance level was set at $\mathrm{p}<0.05$.

\section{Results}

On the basis of the well-defined predetermined spatial considerations, safety guidelines, implant failure criteria, inclusion criteria, and the exclusion criterion, of 945 implant dentistry patients, 106 cases were selected. The total number of implants that showed error was 170 dental implants. The mean number of dental implants with malpractice per patient was (mean $=1.60 \pm 1.084)$ range $[1-8]$. Two partially edentulous male patients had implant fracture, and each patient had one fractured implant placed in the maxilla; one fractured implant was anterior and the other one was posterior; both fractured implants were abutments in implantsupported short span conventional fixed bridges.

\section{Patients and the Number of Dental Implants}

Chi-Square Test showed that there was a significant difference in the percentages of patients distributed by the number of dental implants with malpractice $\mathrm{p}=0.000<0.05$. One or two implants were inserted in $87.7 \%$ of patients; $97.1 \%$ of patients received up to four implants (Table 2).

\section{Implant Malpractice and Patients' Gender and Age}

Chi-Square Test showed that there was a significant difference between the percentage of female patients $\mathrm{n}=65(61.3 \%)$ and that of male patients $\mathrm{n}=41$ $(38.7 \%) \mathrm{p}=0.020<0.05$. Also, Chi-Square Test showed that there was a significant difference in the percentages of patients distributed by different age groups $\mathrm{p}=0.001<0.05$ (Table 3$)$.

\section{Jaw}

Chi-Square Test showed that there was an insignificant difference between the percentage of patients who had implants with malpractice placed in the maxilla and that of patients who had them placed in the mandible $p=0.778>0.05$. Therefore, the two aforementioned percentages were equally divided. 
Table 2: Distribution of patients by the number of implants

\begin{tabular}{|l|c|}
\hline $\begin{array}{l}\text { Number of implants } \\
\text { with malpractice }\end{array}$ & $\mathrm{n}(\%)$ \\
\hline One implant & $67(63.2)$ \\
Two implants & $26(24.5)$ \\
Three implants & $7(6.6)$ \\
Four implants & $3(2.8)$ \\
Five implants & $2(1.9)$ \\
$\geq$ Six implants & $1(0.9)$ \\
Total & $106(100)$ \\
\hline
\end{tabular}

\section{Implant Malpractice and Region}

Chi-Square Test was used to test the significance of differences in the percentages of patients with respect to region (Table 4). Also, Chi-Square Test showed that there was a significant difference between the percentage of patients who had implants with malpractice placed in the posterior region $n=92(80.7 \%)$ and that of patients who had them placed in the anterior region $n=22(19.3 \%) p$ $=0.000<0.05$.

Table 5: Distribution of patients by the timing of technical error

\begin{tabular}{|l|c|c|}
\hline $\begin{array}{l}\text { Timing of } \\
\text { Technical Error }\end{array}$ & $\mathrm{n}(\%)$ & $\mathrm{p}$-value \\
\hline $\begin{array}{l}\text { Preoperative } \\
\text { Yes } \\
\text { No } \\
\text { Total }\end{array}$ & $\begin{array}{l}90(84.9) \\
16(15.1) \\
106(100)\end{array}$ & $\begin{array}{c}\mathrm{p}=0.000<0.05 \\
\text { significant } \\
\text { difference }\end{array}$ \\
\hline $\begin{array}{l}\text { Intraoperative } \\
\text { Yes }\end{array}$ & $87(82.1)$ & $\mathrm{p}=0.000<0.05$ \\
No & $19(17.9)$ & $\begin{array}{c}\text { significant } \\
\text { difference }\end{array}$ \\
Total & $106(100)$ & $\mathrm{p}=0.000<0.05$ \\
Postoperative & $84(79.2)$ & $\begin{array}{c}\text { significant } \\
\text { difference }\end{array}$ \\
Yes & $22(20.8)$ \\
No & $106(100)$ & \\
Total & & \\
\hline
\end{tabular}

Table 3: Distribution of patients by age groups

\begin{tabular}{|c|c|}
\hline $\begin{array}{l}\text { Age Group, } \\
\text { Years }\end{array}$ & $\mathrm{n}(\%)$ \\
\hline$<30$ & $10(9.4)$ \\
$30-40$ & $28(26.4)$ \\
$41-49$ & $19(17.9)$ \\
$50-60$ & $34(32.1)$ \\
$>60$ & $15(14.2)$ \\
Total & $106(100)$ \\
\hline
\end{tabular}

\section{Timing of Technical Error}

Chi-Square Test was used to test the significance of differences in the percentages of patients with respect to preoperative, intraoperative, and postoperative phases (Table 5).

Also, Chi-Square Test showed that there was an insignificant difference in the percentages of patients distributed by the timing of technical error $p$ $=0.902>0.05$; therefore, the percentages of patients were equally divided among the three aforementioned phases.

Table 4: Distribution of patients by regions

\begin{tabular}{|c|c|c|}
\hline Region & $\mathrm{n}(\%)$ & p-value \\
\hline $\begin{array}{l}\text { Anterior } \\
\text { Yes Malpractice } \\
\text { No Malpractice } \\
\text { Total }\end{array}$ & $\begin{array}{l}22(20.8) \\
84(79.2) \\
106(100)\end{array}$ & $\begin{array}{c}\mathrm{p}=0.000<0.05 \\
\text { significant } \\
\text { difference }\end{array}$ \\
\hline $\begin{array}{l}\text { Posterior } \\
\text { Yes Malpractice } \\
\text { No Malpractice } \\
\text { Total }\end{array}$ & $\begin{array}{l}92(86.8) \\
14(13.2) \\
106(100)\end{array}$ & $\begin{array}{c}\mathrm{p}=0.000<0.05 \\
\text { significant } \\
\text { difference }\end{array}$ \\
\hline
\end{tabular}

\section{Violation of Surrounding Structures}

Chi-Square Test showed that there was an insignificant difference between the percentage of patients who had technical errors violating the surrounding structures and that of patients who didn't have them $p=0.174>0.05$. Therefore, the 
two aforementioned percentages were equally divided.

Also, Chi-Square Test was used to test the significance of differences in the percentages of patients with respect to damage to adjacent tooth, inferior alveolar nerve damage, invasion of maxillary sinus (sinus penetration) (Table 6).

Violation of Surrounding Structures and Age and Gender

At the patient level, Spearman's Correlation Coefficient showed that there was an insignificant relationship between each of the damage to adjacent tooth, the inferior alveolar nerve damage, the sinus penetration and the gender of the patient $\mathrm{p}=0.549>$ $0.05, \mathrm{p}=0.306>0.05, \mathrm{p}=0.070>0.05$, respectively. Also, at the patient level, Spearman's Correlation Coefficient showed that there was an insignificant relationship between each of the damage to adjacent tooth, the inferior alveolar nerve damage, the sinus penetration and the age of the patient $\mathrm{p}=0.831>0.05, \mathrm{p}=0.642>0.05, \mathrm{p}=0.274$ $>0.05$, respectively.

Table 6: Distribution of patients by types of violation of surrounding structures

\begin{tabular}{|l|c|c|}
\hline Type of Violation of Surrounding Structures & $\mathrm{n}(\%)$ & $\mathrm{p}$-value \\
\hline Damage to Adjacent Tooth & $40(37.7)$ & $\mathrm{p}=0.012<0.05$ \\
Yes & $66(62.3)$ & significant difference \\
No & $106(100)$ & \\
Total & $12(11.3)$ & $\mathrm{p}=0.000<0.05$ \\
\hline Inferior Alveolar Nerve Damage & $94(88.7)$ & significant difference \\
Yes & $106(100)$ & \\
No & & \\
Total & $5(4.7)$ & $\mathrm{p}=0.000<0.05$ \\
\hline Sinus Penetration & $101(95.3)$ & significant difference \\
Yes & $106(100)$ & \\
No & \\
Total & \\
\hline
\end{tabular}

\section{Implant Failure}

Chi-Square Test showed that there was a significant difference between the percentage of patients who had implant failure $\mathrm{n}=80(75.5 \%)$ and that of patients who didn't have it $\mathrm{n}=26(24.5 \%) \mathrm{p}=0.000$ $<0.05$.

At the patient level, Chi-Square Test showed that there was an insignificant difference between the percentage of patients who had implant failure in the maxilla and that of patients who had it in the mandible $\mathrm{p}=0.377>0.05$. Therefore, the two aforementioned percentages were equally divided.

At the patient level, Spearman's Correlation Coefficient showed that there was an insignificant relationship between implant failure and the gender of the patient $p=0.069>0.05$. Also, at the patient level, Spearman's Correlation Coefficient showed that there was an insignificant relationship between implant failure and the age of the patient $\mathrm{p}=0.789$ $>0.05$.

\section{Peri-implantitis}

Chi-Square Test showed that there was a significant difference between the percentage of patients who had peri-implantitis $\mathrm{n}=22(20.8 \%)(95 \% \mathrm{CI}=$ $12.8 \%$ to $28.7 \%$ ) and that of patients who didn't have it $\mathrm{n}=84(79.2 \%) \mathrm{p}=0.000<0.05$.

At the patient level, Spearman's Correlation Coefficient showed that there was an insignificant relationship between peri-implantitis and the gender of the patient $p=0.812>0.05$. However, at the patient level, Spearman's Correlation Coefficient showed that there was a significant relationship between peri-implantitis and the age of the patient $\mathrm{p}=0.019<0.05$ Correlation Coefficient $=22.7 \%$. With respect to peri-implantitis and age, at the patient level, Chi-Square Test showed that there was 
a significant difference between the percentage of patients $\geq 50$ years of age $n=16(72.7 \%)$ and that of patients $<50$ years of age $n=6(27.3 \%) p=0.033<$ 0.05 .

At the patient level, Chi-Square Test showed that there was an insignificant difference between the percentage of patients who had peri-implantitis in the maxilla and that of patients who had it in the mandible $\mathrm{p}=0.532>0.05$. Therefore, the two aforementioned percentages were equally divided. Also, at the patient level, Spearman's Correlation Coefficient showed that there was an insignificant relationship between peri-implantitis and the maxillary jaw of the patient $\mathrm{p}=0.622>0.05$.

\section{Prosthetic Complications}

Chi-Square Test showed that there was a significant difference between the percentage of patients who had prosthetic complications $\mathrm{n}=20(18.9 \%)$ and that of patients who didn't have them $\mathrm{n}=86$ $(81.1 \%) \mathrm{p}=0.000<0.05$.

At the implant level, of $n=170$ implants with malpractice, $\mathrm{n}=2$ implants were found fractured $(1.17 \%)$.

Chi-Square Test showed that there was a significant difference between the percentage of patients who had implant fracture $n=2(1.9 \%)$ and that of patients who didn't have it $\mathrm{n}=104(98.1 \%) \mathrm{p}=$ $0.000<0.05$.

\section{Discussion}

Implant fracture is rare, ${ }^{13-15}$ and it occurs with narrow diameter implants specifically where the bony wall is thin. ${ }^{13}$ For instance, at the implant level, Eckert et $\mathrm{al}^{16}$ found that implant fracture occurred more frequently in partially edentulous prostheses $(1.5 \%$ incidence $)$ than in completely edentulous ones $(0.2 \%$ incidence $)$, and all fractured implants were of narrow diameter $3.75 \mathrm{~mm}$. Also, in consistence with the present study, Gunne et $\mathrm{al}^{17}$ found that of 521 implants placed in partially edentulous patients, three implants were lost due to fracture $(0.57 \%)$, and all of them were placed in the maxilla. In addition, in agreement with the present study, Goodacre and colleagues found that the mean incidence of implant fracture was $(1 \%)$ at the implant level. ${ }^{18}$

With respect to peri-implantitis, the findings of the present study are consistent with those of literature. For instance, at the patient level, it was found that the prevalence of peri-implantitis in Riyadh city, Saudi Arabia was 27\%, ${ }^{19}$ and Mombelli et $\mathrm{al}^{20}$ found that the prevalence of peri-implantitis was $20 \%$ patients during 5 to 10 years after implantation. In Belgium, a positive correlation was found between peri-implantitis and age; patients aged $\geq 65$ years were prone to peri-implantitis (OR $=1.39) .{ }^{21}$ However, in Sweden, it was found that age didn't influence the probability for subjects to exhibit peri-implantitis. ${ }^{22}$ In Belgium, Marrone et $\mathrm{al}^{21}$ found no association between peri-implant disease and gender. Also, in Sweden, Fransson et $\mathrm{al}^{22}$ found that gender and jaw location didn't influence the probability for subjects to exhibit periimplantitis. In addition, in their review study, Dreyer and colleagues statistically analyzed studies that found relationship between age, male gender, maxillary implants and peri-implantitis with studies that didn't find the aforementioned relationship; they concluded that there is medium-high evidence that patient's age (effect summary OR $1.0,95 \% \mathrm{Cl}$ 0.87-1.16), gender, and maxillary implants are not related to peri-implantitis. ${ }^{23}$

With respect to implant Failure, the findings of present study are in accordance with those previously reported. For instance, Moy at $\mathrm{al}^{24}$ found that gender was not associated with a significant increase in implant failure. Also, Dao et $\mathrm{al}^{25}$ concluded that implant failure rate is not correlated with age and gender. In addition, Grant and Kraut ${ }^{26}$ concluded that age is not a risk factor contributing to implant failure.

In Romania, Clark et $\mathrm{al}^{27}$ found 160 cases of implant malpractice; the total number of dental implants with malpractice was 454 , and the average number of dental implants with error placed per patient was $2.86 \pm 1.97$ with (range 1-9); eight implants were found fractured $(1.76 \%)$. In the present study, in exactly half of the cases examined, 
the maxilla was involved in the malpractice; however, in Romania, it was involved in over half of the cases $n=94(58.7 \%)$. In agreement with the present study, Clark et $\mathrm{al}^{27}$ found that more than half of the patients with malpractice were females $n=91$ $(57.5 \%)$, and patients who had implants placed in the posterior region were more $n=131(66.1 \%)$ than those who had them placed in the anterior region $\mathrm{n}=67$ (33.8\%). In addition, in Romania, Clark et $\mathrm{al}^{27}$ found that of 160 cases with implant malposition complications, 62 cases showed infringement of the implant to adjacent anatomic structure plus 15 cases of adjacent tooth injury; therefore, roughly half of the cases $n=77$ (48.1\%) had implant malpractice violating the anatomic surrounding structures.

In Italy, Pinchi et $\mathrm{al}^{12}$ found 121 cases of implant malpractice; the total number of dental implants with malpractice was 411 . The number of patients who received one or two implants with malpractice was higher in the present study than in Italy (87.7\%) and $(49.6 \%)$, respectively; however, in both studies, over $90 \%$ of patients received up to four implants with malpractice $(97.1 \%)$ and $(92.6 \%)$, respectively. Although there are some discrepancies between the findings of the present study and those found in Italy, many of the findings of both studies are consistent. First, in the present study and in Italy, of all age groups, the highest percentage of cases was seen in the age group 50-60 years $(32.1 \%)$ and $(60.3 \%)$, respectively; second, of all age groups, patients $>60$ years of age $(14.2 \%$ and $28.1 \%)$ were more than patients $<30$ years of age $(9.4 \%$ and $0.8 \%$ ), respectively (Chart 1$)$. Third, in Italy, more than half of the patients with malpractice were females $n=89$ (73.6\%). Fourth, in Italy, Pinchi and colleagues found that half of the patients $n=61$ (50.4\%) had technical errors involving the surrounding structures. Fifth, in the present study and in Italy, the percentages of patients in the intraoperative phase were almost equal (82.1\%) and $(82.6 \%)$, respectively. Concerning the discrepancies between the two studies, the percentages of patients in the preoperative phase were higher in the present study than in Italy (84.9\%) and (52.1\%), respectively. Also, in the present study, the maxilla was involved in the malpractice in exactly half of the cases, while it was involved in over half of the cases $\mathrm{n}=65(53.7 \%)$ in Italy. In addition, the percentages of inferior alveolar nerve damage and sinus penetration were higher in Italy than in the present study (Chart 2). Furthermore, in Italy, in the majority of cases examined, technical errors occurred during the intraoperative phase. On the other hand, in Saudi Arabia, they were equally found during the preoperative, intraoperative, and postoperative phases.

In Saudi Arabia, Al-Safadi et $\mathrm{al}^{28}$ found that patients who had implant positional failure due to preoperative inappropriate treatment planning were equal to those who had it due to intraoperative poor surgical execution.

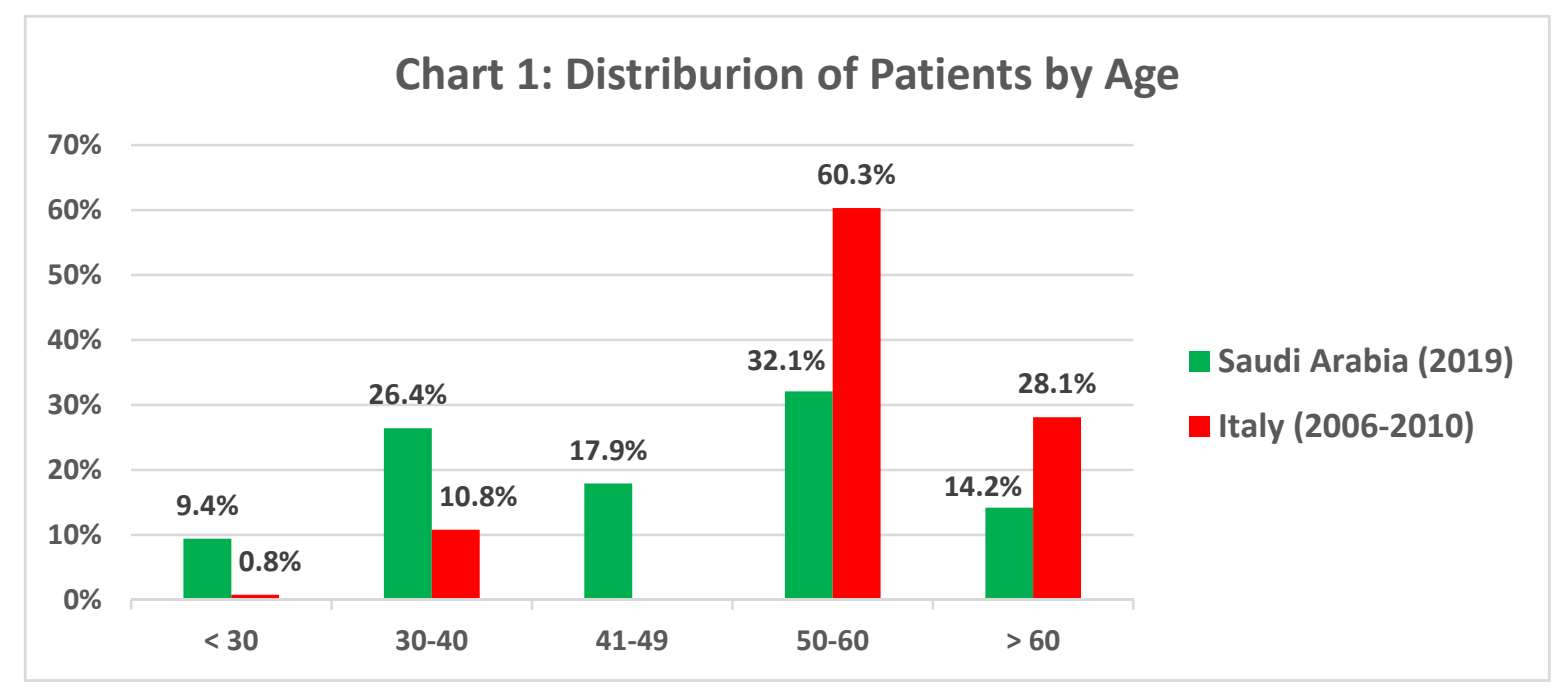




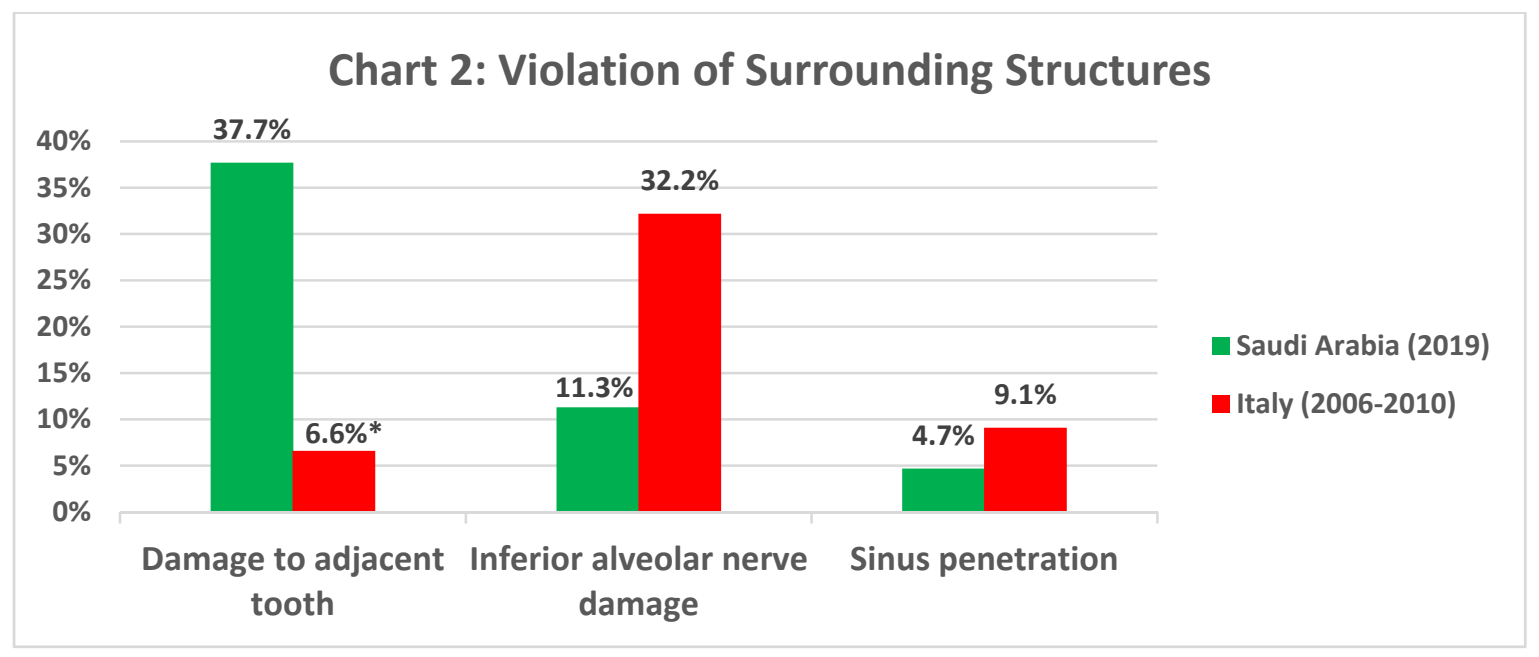

*Pulpal dental necrosis of an adjacent tooth near the implant site

\section{Conclusion}

In the cases examined, the results of this study indicated that implant malpractice equally occurred among the preoperative (diagnosis and treatment planning), intraoperative (during implant insertion), and postoperative (postsurgery and prosthesis) phases. Sound theoretical knowledge and skillful surgical execution are key success factors.

\section{Funding: None}

Conflict of Interest: None declared

\section{References}

1. Dental Malpractice Law and Legal Definition. USLegal. https://definitions.uslegal.com/d/dentalmalpractice/. Accessed November 27, 2019.

2. Dental implants: benefit and risk. NIH Consens Statement. 1978;1(3):13-19.

3. Forum SJ. Implant complications: scope of the problem. In: Forum SJ, ed. Dental Implant Complications: Etiology, Prevention, and Treatment. Oxford: Wiley-Blackwell; 2010:1-8.

4. Albrektsson T, Zarb G, Worthington P, Eriksson AR. The long-term efficacy of currently used dental implants: a review and proposed criteria of success. Int J Oral Maxillofac Implants. 1986;1(1):11-25.

5. Roos J, Sennerby L, Lekholm U, Jemt T, Grödahl $\mathrm{K}$, Albrektsson T. A qualitative and quantitative method for evaluating implant success: a 5-year retrospective analysis of the Brånemark implant. Int J Oral Maxillofac Implants. 1997;12(4):504-514.
6. Rosenberg ES, Evian CI, Stern JK, Waasdorp J. Implant failure: prevalence, risk factors, management, and prevention. In: Forum SJ, ed. Dental Implant Complications: Etiology, Prevention, and Treatment. Oxford: WileyBlackwell; 2010:110-118.

7. Byrne G, ed. Fundementals of Implant Dentistry. Ames, Iowa: John Wiley \& Sons; 2014.

8. ADA Council on Scientific Affairs. Dental endosseous implants: an update. $J$ Am Dent Assoc. 2004;135(1): 92-97.

9. Chee W, Jivraj S. Failures in implant dentistry. $\mathrm{Br}$ Dent J. 2007;202(3):123-129.

10. Chen ST, Buser D. Esthetic complications due to implant malpositions: etiology, prevention, and treatment. In: Forum SJ, ed. Dental Implant Complications: Etiology, Prevention, and Treatment. Oxford: Wiley-Blackwell; 2010:134155.

11. Pi-Anfruns J. Complications in implant dentistry. Alpha Omegan. 2014;107(1):8-12.

12. Pinchi V, Varvara G, Pradella F, Focardi M, Donati MD, Norelli G. Analysis of professional malpractice claims in implant dentistry in Italy from insurance company technical reports, 2006 to 2010. Int J Oral Maxillofac Implants. 2014;29(5):11771184.

13. Palmer RM, Howe LC, Palmer PJ, eds. Implants in Clinical Dentistry. $2^{\text {nd }}$ ed. London: Informa Healthcare; 2012. 
14. Eckert SE, Salinas TJ. Implant fractures: etiology, prevention, and treatment. In: Forum SJ, ed. Dental Implant Complications: Etiology, Prevention, and Treatment. Oxford: WileyBlackwell; 2010:100-109.

15. Sanivarapu S, Moogla S, Kuntcham RS, Kolaparthy LK. Implant fractures: rare but not exceptional. $J$ Indian Soc Periodontol. 2016;20(1):6-11.

16. Eckert SE, Meraw SJ, Cal E, Ow RK. Analysis of incidence and associated factors with fractured implants: a retrospective study. Int $J$ Oral Maxillofac Implants. 2000;15(5): 662-667.

17. Gunne J, Jemt T, Lindén B. Implant treatment in partially edentulous patients: a report on prostheses after 3 years. Int J Prosthodont. 1994;7(2):143-148.

18. Goodacre CJ, Bernal G, Rungcharassaeng K, Kan JY. Clinical complications with implants and implant prostheses. J Prosthet Dent. 2003; 90(2):121-132.

19. AlGhamdi J, Shafik S, Al-Mashat H. Prevalence of peri-implant diseases among patients received dental implants at Riyadh city, KSA. Int J Appl Res. 2017;3(7): 792-797.

20. Mombelli A, Müller N, Cionca N. The epidemiology of peri-implantitis. Clin Oral Implants Res. 2012;23(Suppl 6):67-76.

21. Marrone A, Lasserre J, Bercy P, Brecx MC. Prevalence and risk factors for peri-implant disease in Belgian adults. Clin Oral Implants Res. 2013;24(8):934-940.

22. Fransson C, Lekholm U, Jemt T, Berglundh T. Prevalence of subjects with progressive bone loss at implants. Clin Oral Implants Res. 2005;16(4):440446.

23. Dreyer H, Grischke J, Tiede C, et al. Epidemiology and risk factors of peri-implantitis: a systematic review. $J$ Periodontal Res. 2018;53(5):657-681.

24. Moy PK, Medina D, Shetty V, Aghaloo TL. Dental implant failure rates and associated risk factors. Int $J$ Oral Maxillofac Implants. 2005;20(4):569-577.

25. Dao TT, Anderson JD, Zarb GA. Is osteoporosis a risk factor for osseointegration of dental implants?. Int $J$ Oral Maxillofac Implants. 1993;8(2):137-144.

26. Grant BT, Kraut RA. Dental implants in geriatric patients : a retrospective study of 47 cases. Implant Dent. 2007;16(4):362-368.

27. Clark D, Barbu H, Lorean A, Mijiritsky E, Levin L. Incidental findings of implant complications on postimplantation CBCTs: a cross-sectional study. Clin Implant Dent Relat Res. 2017;19(5):776-782. 28. Al-Safadi R, Al-Safadi R, Al-Safadi R, et al. Dental malpractice in implant dentistry in Saudi Arabia: preoperative and intraoperative complications. Int J Emerg Trends Sci Technol. 2019;6(11):6844-6854. 